\title{
Diversidade pedagógica de formação humana no ideário democrático em escolas confessionais
}

\section{Pedagogical diversity of human formation in the democratic ideal in confessional schools}

\author{
Jardel Costa Pereira \\ Orcid: 0000-0003-0978-2873 \\ Doutor em Educação Escolar, Universidade do Estado de Minas Gerais, Leopoldina, \\ Brasil, jardel.pereira@uemg.br \\ Geyza Spitz Alcoforado de Abreu \\ Orcid: 0000-0001-7826-7694 \\ Doutora em Educação, Universidade do Estado de Santa Catarina, Florianópolis, Brasil, \\ geysa.udesc@gmail.com \\ Loyde Anne Carreiro Silva Veras \\ Orcid: 0000-0001-7755-2434 \\ Doutoranda em Educação pelo Programa de Pós-Graduação em Educação da Pontifícia \\ Universidade Católica do Paraná, Curitiba, Brasil, loydeanne08@gmail.com
}

Received on 20/04/2020 - Approved on 21/04/2020

\begin{abstract}
This article analyzes the establishment of three confessional schools and their educational projects established in the late 19th and mid 20th centuries. The intention is to perceive them as guiding plural pedagogical practices, when school identity, other than Catholic, was under construction in Brazil. A bibliographic review was used with a diversified theoretical framework according to the research carried out. It is concluded that there was the opening and establishment of a fertile soil for educational projects, which favored the performance of intellectuals linked to a specific religion.

Keywords: Confessional Teaching. School Culture. Protestantism. Religious Plurality. Laic State.

\section{Resumo}

Este artigo analisa o estabelecimento de três escolas protestantes e seus projetos educacionais estabelecidos no final do século XIX e nos meados do século XX. Têm-se o intuito de percebê-los como norteadores de práticas pedagógicas plurais, quando a identidade protestante estava em construção no Brasil. Utilizou-se de uma revisão bibliográfica com um referencial teórico diversificado de acordo com as pesquisas realizadas. Conclui-se que houve a abertura e o estabelecimento de um solo fértil de projetos educacionais o que favoreceu a atuação de intelectuais vinculados a uma religião específica.
\end{abstract}

Palavras-chave: Ensino Confessional. Cultura Escolar. Protestantismo. Pluralidade Religiosa. Estado Laico. 


\title{
Introdução
}

O domínio da religião católica como a única existente em terras brasileiras perdurou até 1824, quando, por uma Constituição, permitiu-se uma certa tolerância religiosa; somente com a Proclamação da República e sua primeira Constituição, promulgada em 24 de fevereiro de 1891, é que procurou se estabelecer um Estado mais laico, com a criação de cemitérios, sem ser os católicos, permitindo que as outras religiões também tivessem seus templos e, consequentemente, maior liberdade de culto. Isso só foi possível a partir da extinção do poder monárquico o que influenciou o surgimento de novos modelos educacionais:

\begin{abstract}
Es posible sostener que a lo largo de la historia se evidencian diferentes modelos pedagógicos, cada régimen político buscó instaurar, mediante discursos, su ideal. Estos discursos atesoran una importancia crucial, esto porque en el devenir histórico lograron imprimirse en prácticas, imágenes, recursos didácticos, reglamentos, planes de estudio, manuales escolares, entre otros. Logrando construir una trama que busco imprimir en los cuerpos ideas, saberes, prácticas que debían adecuarse a los procesos históricos-políticos, sociales y culturales, en hombres y mujeres, dando lugar a un sujeto pedagógico específico del período (Maciel, 2018, p. 8).
\end{abstract}

Conforme Maciel em seu artigo 'Educación religiosa y regulaciones del cuerpo: la formação de niñas. Salta a fines del siglo XIX', publicado na Revista History of Education in Latin America (HistELA), com um novo regime político, o Republicano, novos ideais surgiram. A partir deste contexto, deu-se a continuidade de construção da identidade de outros grupos religiosos, dentre eles os Presbiterianos, que vindos de diversas partes da Europa e dos Estados Unidos da América se inseriram na sociedade brasileira disputando espaços urbanos e escolares principalmente com os católicos. Muitos desses homens e mulheres tiveram uma atuação importante na constituição de ideários pedagógicos, fundando escolas e até mesmo atuando em cargos governamentais, onde contribuíram com reformas educacionais. Nesse artigo serão apresentados três estudos, sendo dois sobre as missões protestantes vindas dos Estados Unidos e um sobre a atuação protestante inglesa.

\section{Cultura escolar, religiosa e a educação secundária presbiteriana no sul das Minas Gerais}

No ano de 1892, a cidade de Lavras recebia em suas terras uma religião diferente da católica: a Presbiteriana. O início dos trabalhos da Igreja Presbiteriana no Brasil ocorreu em 1859, na cidade do Rio de Janeiro, e, em 1860, em terras paulistas, com americanos vindos do Sul dos Estados Unidos. Em 1871 começaram as atividades religiosas na cidade de Campinas, no interior do Estado de São Paulo, onde foi fundado um colégio, e a partir daí vários missionários 
vieram para um trabalho evangelizador e educacional, dentre os quais se encontravam Samuel Rhea Gammon' e Carlota Kemperii. Após uma epidemia de febre amarela, que ocasionou a morte de muitas pessoas e até de missionários, 0 grupo que ainda estava em Campinas decidiu mudar-se para a cidade de Lavras, no interior do Estado de Minas Gerais.

Nos primórdios do estabelecimento das missões presbiterianas em Campinas, a educação secundária foi a mais desenvolvida, se despontando como propedêutica, e toda a organização dessa etapa de formação foi apresentada nos Prospectos iii, em formato de artigos, com leis e parágrafos, seguindo as prescrições do Ginásio Nacionaliv .

Em Lavras, mesmo com os problemas financeiros, houve um investimento na construção de prédios, como o do salão nobre, que, em sua inauguração em 1909, trouxe no frontispício do palco o lema do Instituto Evangélico: "Dedicado à glória de Deus e ao progresso humano". Um outro prédio também fora construído e denominado de 'A porta da oportunidade'.

$\mathrm{Na}$ perspectiva presbiteriana, todas as faculdades humanas deveriam ser desenvolvidas e nem todos os alunos queriam ou teriam capacidade e condições de fazer um curso superior. Assim eram oferecidas outras opções, como "a porta da oportunidade", que poderiam, no futuro, Ihes garantir um emprego, seja na roça, seja no comércio como funcionários em alguma repartição ou abrindo o próprio negócio, com base no que aprenderam nas oficinas. O importante era, por meio do ensino, fundamentado em princípios morais e religiosos, inserir homens e mulheres na sociedade para a construção de um mundo melhor, fundamentado na doutrina presbiteriana, por isso havia a preocupação com uma formação integral com oferecimento de diversos cursos.

$\mathrm{Na}$ acolhida dos alunos do ginásio, tanto masculino quanto feminino, o recurso utilizado foram os internatos, que foram usados com a finalidade de instruir, seja religiosamente ou intelectualmente. Esse foi o regime dominante utilizado pelos presbiterianos em Lavras desde o início da missão, sendo exposto no Prospecto de 1908 (p. 7), demonstrando a seriedade como era visto esse tipo de ensino. Para a caracterização dos internatos construídos no Instituto, foi feita a opção de trabalhar as categorias faixa etária, dormitórios, uniformes e disciplina, o que indica como era feito o controle dos corpos, conforme caracterizado por Foucault (2013, p. 142-143).

Em 1921, já estavam construídos vários dormitórios para acolher os meninos, que eram a maioria, e que estavam organizados nos princípios higiênicos para que a vida colegial tivesse um bom desenvolvimento. Nos prospectos as informações dos internatos por escola são separadas, ficando o internato feminino no centro da cidade, bem distante do masculino.

Para a escola de meninas houve, também, a prescrição do controle dos corpos, instituindo regras como a indicação de pessoas que as meninas podiam receber e como respeitar os horários permitidos para visitas. Aos domingos, somente os familiares das alunas podiam visitá-las, sendo a idade mínima, para acolhimento no internato feminino, de 10 anos. Para cada gênero havia um espaço com regras diferenciadas, demonstrando qual era o objetivo e a formação específica, conforme a vida social demandava. Havia, também, regras diferenciadas conforme as circunstâncias e as meninas, no internato, só recebiam visitas de homens, desde que identificados, demonstrando, assim, o recato e a preservação necessários do sexo feminino. 
Isso também se estendia aos uniformes diferenciados, não se exigindo, para as meninas externas ao Colégio Kemper "[...] uniforme rigoroso, mas as alumnas internas devem ter uma saia de azul marinho, tres blusas brancas, meias e sapatos pretos, devendo toda a roupa ser marcada claramente com o nome da alumna" (PROSPECTO das Escolas do Instituto Evangélico, 1925. p. 37) ${ }^{v}$. Para os meninos, não se exigia uniforme, apenas que tivessem ternos para o uso diário, e, para sair, não havia a exigência de identificação. No parecer de Hunt (1995, p. 24), o gênero se tornou ao longo dos anos "[...] uma das mais críticas configurações de diferenciação na cultura e sociedade. Sem alguma discussão do gênero, nenhum relato de unidade e diferenças culturais pode estar completo". Para Vago (2002, p. 136), a uniformização por meio da vestimenta escolar indicava que havia um desejo também de esconder as desigualdades sociais, que seriam visíveis nos corpos dos alunos.

As regras disciplinares também aparecem nos prospectos com o intuito de informar os pais dos alunos ou aqueles que queriam maiores informações sobre todo o sistema educacional do Instituto Evangélico e elas foram sendo alteradas ou acrescentadas conforme as necessidades e o que ocorria de errado.

No Prospecto de 1908 (p. 13), as normas comportamentais estão inseridas numa parte intitulada "Disposições gerais", e o artigo 3ํㅜ foi reproduzido em sua íntegra em todos os outros chamando a atenção de que a família é responsável pela disciplina dos filhos ${ }^{\mathrm{vi}}$, que deve ser branda e firme ao mesmo tempo. Era permitido o passeio aos sábados pela cidade desde que retornassem antes no anoitecer. À noite, em qualquer dia, era proibido sair do Instituto e também frequentar o teatro ou "[...] outros espetáculos que possam offender a moral" (PROSPECTO do Instituto Gammon, 1908. p. 13). Depois de mais de uma década, as regras de comportamento apresentadas no Prospecto de 1921 foram as mesmas reproduzidas em todos os outros até 1941. De diferente das normas apresentadas no Prospecto de 1908, no de 1921 estava a proibição de manifestações de desobediência ou reinvindicação feitas por meio de greves, ou sair do intervalo sem permissão, sendo a pena a expulsão do aluno da escola. Era também obrigação participar dos cultos evangélicos, sendo proibido o uso de cigarros, de bebidas alcóolicas e portar armas de fogo.

No cerceamento dos corpos, todas as situações tidas como perigosas são elencadas, acontecendo, algumas delas, no interior da escola, como a morte de um aluno por um outro colega, vítima de arma de fogo, relatado por Gammon (1959, p. 142). A partir desse fato foi criada a lei de proibição do uso de armas de fogo, o que caracteriza o descontrole dos corpos mesmo havendo normas e regras a respeitar. As leis são burladas, a indisciplina foge do controle e medidas mais drásticas são tomadas. No caso do aluno Alexandre, os princípios cristãos sobressaíram nas punições tomadas a ele, o que não aconteceu quando houve um princípio de greve no Instituto, por ter aulas aos sábados que era feriado e ao se depararem com o diretor, ele Ihes propôs ou voltarem para casa ou seriam considerados hóspedes, o que fez cada um voltar e escrever um abaixo assinado se desculpando: "[...] E, na realidade, medidas severas estavam sendo tomadas pela Diretoria [...]. Daquela data fêz parte do Regulamento uma cláusula proibindo greves e cominando penas severas para esta falta (Gammon, 1959, p. 146).

No parecer de Julia (2001, p. 19), as normas e as práticas que regem uma escola "[...] devem sempre nos reenviar às práticas". A partir da lei inscrita, as penalidades podiam ser aplicadas e, em outros casos, o que não constava no Prospecto era decidido entre os próprios professores e diretor, como excluir um 
aluno do recreio ou dos esportes, por nota baixa ou mau comportamento. Com essas práticas disciplinares, procurava-se instalar uma ordem escolar a ser cumprida com rigor, transformando alunos e alunas em cidadãos que deveriam, no futuro, ser frequentes, "[...] pontuais, assépticos, obedientes, disciplinados e servis, atentos, quietos e comportados, cordiais, amigos e carinhosos" (Vago, 2002, p. 129), o que se aproxima dos conceitos foucaultinos: "A disciplina fabrica assim corpos submissos e exercitados, corpos 'dóceis"' (Foucault, 2013, p. 133).

O diretor também tinha um retorno das medidas disciplinares que tomava. Um pai lhe escreveu contando que estava agradecido, pois seu filho estava mais calmo e pronto para voltar aos estudos, depois de ser enviado em casa para passar alguns dias após um mau comportamento ${ }^{\text {vii }}$.

Outras estratégias e práticas foram criadas na organização estudantil dos alunos, e não somente com intuito de controle, mas também de recreação, tendo um papel social importante e até mesmo moderno, quando parecidas com o que já existia nos Estados Unidos. Por exemplo, no Prospecto de 1937 (p. 6), indica-se que havia no Instituto "várias sociedades literárias, científicas e religiosas", sendo o objetivo dessa parte apresentar como a educação secundária estava inserida nelas, quais eram seus objetivos e como isso tinha características urbanas e finalidades sociais.

A finalidade dessas associações, no parecer de Samuel Gammon, era, além de desenvolver as habilidades de comunicação dos alunos, fazer com que eles se relacionassem entre si, além do objetivo de estudar que os unia como alunos no espaço escolar.

As agremiações e associações criadas no Instituto Evangélico são exemplos de "experiência de socialização" que foram sendo passados de geração em geração e estão presentes até os dias de hoje, como a "Associação dos exalunos", criada em 1931, com o objetivo de "defender os ideais do Instituto, zelar carinhosamente as suas tradições e confraternizar todos os gammonenses do passado e do presente" (O INSTITUTO, P. 1, jun. 1931). Um dia no ano foi escolhido para que houvesse uma grande confraternização de todos na cidade de Lavras, sendo que Gammon (1959, p. 155) indicou os frutos que a escola já estava colhendo: "O Instituto estava crescendo. A Igreja e a cidade também progrediam". Os alunos que já estavam formados em nível superior, já ocupavam cargos importantes: "Três se formaram em medicina, cinco ou mais foram professores, três vieram a ser ministros, um missionário e outro Secretário do Estado".

Juntamente com o progresso educacional também deveria vir o urbano que implicava em tirar os homens de práticas atrasadas, como afirma Veiga (2002), com o objetivo de formar um novo homem, civilizado, com novos hábitos, produzindo, assim, nova civilização.

A escola, inserida no urbano, formadora de mentes e corpos, deveria incutir nos alunos as práticas civilizadas fundamentadas nos aspectos morais e religiosos, perpassando os anos e sendo considerada como um centro de garantia do progresso. Mas as notícias circuladas em jornais apresentavam uma outra realidade, como a vadiagem com o jogo de bolas quebrando vidraças das casas, a ponto de a delegacia de polícia interferir e fazer circular um aviso de que medidas sérias iam ser tomadas, como o recolhimento das bolas e a prisão daqueles que ficavam andando pelas ruas em dia de trabalho (A GAZETA, p. 3, 11 set. 1931). 
No Brasil, a representação da escola nos discursos dos presbiterianos, transformou-se num instrumento importante para a salvação da sociedade. $O$ Ensino Secundário, com a organização de importantes colégios, foi a esperança que os missionários tinham em usar suas escolas para a instrução de seus próprios filhos, como também para formar seus pastores e professores. Com esses propósitos, os ginásios foram abertos também a outras pessoas da comunidade, crentes ou não, esperançosos em dar uma formação escolar aos seus filhos. A elite também soube valorizar as escolas americanas presbiterianas, colocando seus filhos nos internatos, nos ginásios, com 0 intuito de dar continuidade ao seu statu quo.

\section{Presbiterianos no Paraná: a Escola Americana de Curitiba (1892 - 1934)}

A Escola Americana de Curitiba foi fundada em 1892 por missionáriaseducadoras norte-americanas: Miss Mary Parker Dascomb e Miss Elmira Kühl, enviadas ao Brasil pela American Foreign Board - Junta Missionária de Nova York, ligado à Igreja Presbiteriana do Norte dos Estados Unidos e ela começou como uma filial da Escola Americana de São Paulo, posteriormente denominada Mackenzie College. As duas missionárias fundadoras já possuíam experiência como educadoras em seu país de origem e, no Brasil, trabalharam em diversas cidades, como: Rio de Janeiro, Brotas, Rio Claro, Botucatu.

Entendendo-se que a escola é uma instituição social produtora de práticas e representações que amplia, adapta e recria a cultura inclusiva, o estudo do conjunto das características que compõe o modo escolar de transmissão cultural num tempo e espaço definidos, possibilita a compreensão de elementos não priorizados pela historiografia tradicional (Abreu, 2003, p. 02).

Assim, para compreender as práticas geradas e compartilhadas na Escola Americana, o questionamento que orientou este trabalho ${ }^{\text {viii }}$ esteve voltado para os aspectos internos da escola, sem desconsiderar as relações da cultura escolar com culturas que lhe são contemporâneas. Nessa perspectiva, o estudo foi desenvolvido visando trazer à cena a ação educativa dos sujeitos envolvidos, os programas, conteúdos e métodos de ensino, além de aspectos da cultura escolar materializados na organização do espaço escolar; organização do tempo escolar (calendário escolar - período de férias, matrícula, seleção, avaliação; organização geral do tempo - níveis, cursos; organização diária - horário, programação das aulas e das diferentes disciplinas do currículo), rituais escolares (dispositivos de avaliação e classificação, dispositivos de punição e exaltação; exposições escolares) etc.

A preocupação, desde os primeiros tempos do trabalho missionário no Brasil, com a fundação de uma escola logo após a fundação das Igrejas é apontada pela maioria dos estudiosos do protestantismo como decorrente da necessidade de alfabetizar o povo devido ao elevado índice de analfabetismo. Certamente que havia a preocupação de alfabetizar, posto que o culto protestante exige o domínio da leitura, mas a criação de escolas presbiterianas não se justifica somente pela necessidade de alfabetização. A educação para os presbiterianos era antes uma tradição cultural, do que uma estratégia missionária desenvolvida no Brasil. 
Nos Estados Unidos, a evangelização indireta, na qual a ação catequética se realizava concomitantemente com as obras sociais, principalmente escolas e colégios, já era largamente utilizada, tanto quanto a evangelização direta. Para eles, segundo Hilsdorf (1986), "[...] a escola representava a cunha que abriria caminho para as atividades de proselitismo". Assim, com a intenção de servir de elemento de penetração e apoio das atividades catequéticas, as igrejas procuravam instalar escolas paroquiais de primeiras letras que, em centros estratégicos, transformavam-se em colégios de nível médio e mesmo em escolas superiores (Barbanti, 1977, p. 110).

A importância atribuída à educação pelos presbiterianos norte-americanos se observa quando a Junta das Missões tratou de incluir no seu quadro de pessoal professores experientes, principalmente mulheres, para fundar escolas e trabalhar no Brasilix. Na concepção dos presbiterianos norte-americanos, "a educação oferecida pela própria Igreja, poderia: educar os filhos dos membros da Igreja; preparar futuros missionários; contribuir indiretamente na tarefa de evangelização e difusão dos ideais norte-americanosx" (Abreu, 2003, p. 47).

Outra finalidade atribuída às escolas criadas pela Junta Missionária de Nova York era a difusão dos ideais norte-americanos. Assim, princípios evangélicos e ideologia norte-americana eram entendidos como uma coisa só. $\mathrm{O}$ protestantismo presbiteriano se afigurava como a versão religiosa dos ideais modernos, especialmente por trazer o que era entendido como a pedagogia norteamericana:

Iniciativa privada, ensino prático, científico e comum para todos, currículo atualizado, cuidado com os aspectos materiais do ensino, aulas regulares diurnas e conferências públicas noturnas, atividades extraclasse, suporte financeiro do capital associado (Hilsdorf, 1986, pp. 187-188).

É nesse contexto que se pode entender a função modelar que a Escola Americana de São Paulo, fundada em 1870, exerceu para a organização das demais Escolas Americanas fundadas no país, além de ser tomada "como um dos modelos das reformas efetuadas na rede oficial do ensino de São Paulo, a partir de 1890" (Barbanti, 1977, p. 145). Segundo Goldman (1972), ao findar-se o século, os missionários presbiterianos já haviam fundado mais de quarenta escolas primárias, a maioria no Estado de São Paulo, e usualmente denominadas "Escolas Americanas".

Poucos anos depois, o ensino público paulista serviu de padrão para a reorganização do ensino público em diversos estados, como: Minas Gerais, Santa Catarina, Goiás, Sergipe, Paraná, Pernambuco, Piauí, Acre (cf. Souza, 1998, p. $61)$.

$\mathrm{Na}$ Escola Americana de Curitiba, seguindo o modelo pedagógico da Escola Americana de São Paulo, o ensino era ministrado em português. Inicialmente, o trabalho foi dividido em três níveis: Primário, Intermediário e Secundário. Apresentava uma estrutura seriada, seguindo a concepção do ensino intuitivo, considerado a base do ensino moderno. No segundo ano de funcionamento da Escola, organizou-se também uma Classe Normal, revelando a preocupação com a formação de quadros especializados que pudessem dar continuidade ao trabalho iniciado. 
A escola adquiriu rápida projeção em Curitiba: o mobiliário procedente de Nova York a distinguia das demais escolas da cidade e, da mesma forma, boa parte do material, também oriundo dos Estados Unidos, contrastava com a precariedade material das escolas da época. Desde a fundação a Escola já dispunha de piano; mapas; biblioteca composta de dicionários e livros em inglês, alemão, francês e português.

Em 1917, construiu-se um novo prédio para a Escola Americana, especialmente projetado para as salas de aula. A grande procura por matrícula, desde o primeiro ano de funcionamento é indicativa da visibilidade que rapidamente adquiria. A Escola oferecia o regime de internato para meninas, possibilitando que alunas do interior do estado pudessem frequentar as aulas. Este fato contribuiu para que o número de estudantes do sexo feminino fosse sempre superior aos do sexo masculino, um dado pouco comum para a época. $\mathrm{Na}$ Escola Americana de São Paulo, "de 1890 a 1933, a porcentagem de estudantes homens foi sempre superior à de mulheres. Para $69 \%$ de homens que estudavam havia $31 \%$ de mulheres" (Laguna, 1999, p. 59).

No externato, a Escola Americana de Curitiba funcionava em regime de coeducação, atendendo meninos e meninas de diversas nacionalidades. Nas escolas presbiterianas criadas no Brasil no final do século XIX, a exemplo do que ocorria nos Estados Unidos, era comum a presença feminina.

As esposas e filhas dos missionários encarregavam-se de lecionar nas escolas criadas junto às igrejas, assumindo, inclusive, a direção e organização dessas escolas. Os presbiterianos tinham muito cuidado com a formação de todos os missionários e, particularmente, com a formação daqueles que se dedicariam à educação. $O$ valor atribuído pelos presbiterianos à instrução pode ser percebido, por exemplo, pelo envio de educadores norte-americanos para o Brasil. A Junta Missionária de Nova York não somente trouxe educadores para o Brasil, mas também contribuiu pagando salários de educadores nacionais ou ajudando a pagá-los. Nos livros de contabilidade da Escola Americana de Curitiba, observa-se a destinação de verbas do Board das Missões para o pagamento do salário dos professores, bem como para a manutenção geral da Escola. Em 1917, as diretoras-fundadoras da Escola Americana de Curitiba faleceram.

Em fins de 1934, a Escola Americana foi vendida para um membro da Igreja Presbiteriana de Curitiba, o Rev. Luiz Lenz de Araújo César. Acredita-se que o principal motivo da venda tenha sido uma crise vivida pelo Mackenzie devido ao processo de cassação dos diplomas da Escola de Engenharia "Mackenzie College", em 1932, que constituiu a "expressão mais aguda dos conflitos e reveses vividos pela Instituição" (Mendes, 2000, p. 11). Em 1935, o Rev. César inaugurou o Ginásio Belmiro César, que funcionaria com o curso ginasial, paralelamente ao ensino primário ofertado pela Escola Americana de Curitiba. Mais tarde, em 1945, o Colégio Belmiro César passou a oferecer também o curso colegial. Em 1956 essas instituições encerraram definitivamente suas atividades. 


\section{O Colégio Cristão: uma experiência protestante Inter denominacional no interior do Maranhão}

Apesar da separação Igreja/Estado no início da república brasileira, o interesse em um projeto de nação desenvolvimentista no início do século XX, aligeirado pela demanda socioeconômica, bem como a pressão pela universalização do ensino, fez com que políticas de educação em massa fossem deflagradas. Escolas confessionais protestantes se apresentam a partir das demandas sociais (analfabetismo, parcas escolas) e das brechas legais viabilizadas pelas disputas e concessões entre o público, privado e religioso católico nesses contextos.

Toma-se como expressão dessa relação o Colégio Cristão, uma escolainternato protestante Inter denominacional que funcionou entre os as décadas de 1930 e 1940 no interior do Maranhão. Este assumiu diferentes representações em suas funções sociais: a propagação de um projeto missionário protestante no Norte do Brasil, o atendimento a uma demanda de formação de liderança local entre novos grupos de conversos e ainda, e não menos importante, se apresentou como uma opção possível frente aos embates com grupos religiosos católicos, um reduto de sobrevivência de um grupo minoritário em meio às disputas pela liberdade de culto e de expressão.

O Colégio Cristão foi fundado por Eva Mills, uma missionária protestante que veio da Inglaterra para o Brasil no ano de 1928. Sua ação se deu entre os estados do Maranhão, Pará, Ceará e Pernambuco, sobretudo no campo educacional, com a criação e direção de escolas internatos. A experiência de Eva Mills no Brasil é associada a uma tradição protestante histórica, apesar de sua vinda não ser vinculada (inicialmente) a nenhuma denominação ou agência missionária específica ${ }^{\mathrm{xi}}$. Ela e seu marido vieram como missionários independentes para atuarem junto a indígenas e ribeirinhos na região amazônica brasileira.

Em sua autobiografia, a missionária relata sua primeira experiência na cidade de Imperatriz, Maranhão, no ano de 1929. Nessa narrativa, enquanto a autora discorre sobre a conquista do novo grupo de prosélitos que ia se convertendo naquela cidade, ela vai apresentando elementos que dão conta de um clima de conflito e perseguição religiosa em Imperatriz. O espaço público é, aos poucos, requerido pelos da nova religião, através de reuniões nas casas, mas também ao ar livre (ruas e praças públicas), culminando com a construção deliberada de uma sala de reuniões - um templo - no centro da cidade.

Nossa nova pequena sala de reuniões, em lugar tão central da cidade, causou inveja e muitos oponentes do Evangelho ficaram irritados. A perseguição espalhou-se e foi profundamente dolorosa para os crentes. Ensinados pela Palavra, os crentes permaneceram quietos, não retaliaram e começaram a cuidar uns dos outros, a cuidar das necessidades dos aflitos e a lembrar uns dos outros em constante oração. Eles foram crescendo em meio à perseguição. As vidas dos missionários foram ameaçadas várias vezes. A preocupação dos crentes com a nossa segurança causava uma devota vigilância sobre nós. Nessa atmosfera, desenvolvia-se amor fraternal e maturidade espiritual. Isso alegrava nossos corações durante os dias difíceis, 
especialmente quando víamos alguns dos crentes prontos a aceitar a responsabilidade na liderança espiritual. (Mills, 1976, p. 47, tradução livre).

A materialização da presença protestante por meio da construção de um templo no centro da cidade acentuou a perseguição, apresentada como fator de agregação, fortalecimento e surgimento de lideranças locais. Vale retomar o fato de que, desde a proclamação republicana, era perfeitamente legal a construção de tal prédio de cultos ou mesmo as reuniões públicas. Estávamos aqui (nas narrativas da Mills) na década de 1920 no Maranhão, portanto, sob a égide de um Estado laico, mas a resistência por parte de religiosos católicos parecia ainda anterior a 1891, agindo de forma aguerrida, talvez por só agora se sentirem invadidos em seus espaços.

A identidade protestante foi sendo construída nessa relação de conflito e enfrentamento com o outro, na luta de representações (Chartier, 2002), sob imaginários de demonização mútua nas disputas de campo. Enquanto aos protestantes cabia a batalha por uma região dominada por feitiçarias, bruxarias e deuses falsos, eles também foram representados como sendo a própria encarnação do mal que assombrava e invadia a região. Sob a perspectiva protestante, os outros eram os católicos, intolerantes que atacavam e perseguiam; contudo, para muitos, os outros eram os missionários protestantes, forasteiros e estranhos com sua nova religião, que chegavam carregados de mistérios e encantamento.

A ação de Eva Mills diretamente no campo educacional escolar se concretiza em 1933, quase cinco anos depois de sua chegada ao Brasil, na cidade de Balsas, Maranhão, com o início do Colégio Cristão. O desafio de abrir uma escola para "filhos de crentes pobres e analfabetos" (Mills, 1976, p. 11, tradução livre) é o objetivo apresentado pela Mills. A abertura do Colégio é justificada por ela de diferentes formas: primeiro por uma necessidade social, o ambiente "primitivo" e a carência de escolas na região.

A segunda razão apontada por Eva Mills, e esta não é uma ordem de prioridade, é a necessidade pragmática em lidar com crentes sem habilidade com a leitura, aliada ao preparo de uma liderança brasileira para a nova comunidades de convertidos que se formava.

O terceiro motivo para a abertura da escola protestante, não apresentado por Eva Mills de forma contundente em seus livros, mas que permeia toda a sua narrativa e é corroborado por outras memórias da época, são os conflitos religiosos e a intolerância sentida pelo grupo protestante em se inserir ou ser aceito no espaço do grupo religioso já estabelecido, inclusive em suas escolas.

O interior do Maranhão é uma região muito vasta e, naquele momento, sem um processo de integração aos bens e serviços desenvolvidos e oferecidos a partir da Capital, como políticas e recursos voltados para a abertura de escolas e ainda o suprimento de professores formados para o interior, resultara em um número irrisório de escolas de iniciativa pública, principalmente nas regiões mais afastadas do litoral/capital (Castro \& Silva, 2016; Melo, 2012; Cruz, 2013). Em muitos municípios e vilas, as únicas escolas eram privadas de iniciativa católica, junto às missões que iam para o trabalho junto a indígenas, especialmente padres e freiras da ordem Capuchinha.

Sobre a presença de escolas na região deste período, Dugal Smith, um dos ex-alunos de Eva Mills, desenvolve a seguinte narrativa em sua autobiografia: 
Não havia nenhuma escola pública em Barra do Corda. O convento de freiras tinha uma escola para crianças católicas. Nós não podíamos estudar lá porque nossa religião era diferente. Papai e Mamãe se preocupavam com a educação dos filhos, no entanto não podiam fazer nada a respeito. (Smith, 1986, p. 41).

A descrição de que só havia uma escola na cidade e esta não era pública, mas católica, e que eles, os filhos do missionário protestante, não poderiam estudar ali, revela o clima de indisposição e intolerância religiosa que reforça a necessidade de abertura de uma escola para os filhos dos crentes, haja vista estes serem impedidos de estudar nas escolas católicas. A escola em questão se tratava do Grupo Escolar Frederico Figueira, rememorado como a primeira escola pública primária de Barra do Corda. O prédio escolar se encontrava no mesmo terreno da Igreja Matriz da cidade, chegando a chamar-se Ginásio Nossa Senhora de Fátima, depois Colégio Pio XI. Dugal Smith entra como aluno nesta escola por volta do ano de 1929 quando pôde, finalmente, ele e suas irmãs, estudarem formalmente - possivelmente quando realizada a parceria (ou seja, quando ela é tornada "pública") e a escola, antes católica, agora poderia (ou deveria) receber oficialmente membros de outras religiões. Dugal Smith continua a narrativa dizendo que, após a chegada da professora Eva Mills e a abertura de sua escola em Balsas, ele e suas irmãs foram estudar com ela em regime de internato.

Em entrevista registrada por Charles Stoner (Mills, [entrevista] 1985), Eva Mills diz que seus alunos vinham de regiões onde havia alguma pequena congregação de crentes sem a presença de missionários e muita oposição Católica Romana. Estes alunos eram preparados não só para a subsistência do grupo, suprindo sua própria necessidade de uma liderança habilitada à prática da leitura, quanto para lidarem em frentes de batalha junto a um grupo rival.

Uma entrevista com Abdoral Fernandes da Silva, registrada por Veras (2005) - cujo objetivo era compreender os conflitos gerados pela expansão protestante no interior do Estado do Maranhão - traz o seguinte relato sobre o tempo em que este foi aluno no Colégio Cristão de Colinas, Maranhão.

\footnotetext{
Sempre a gente se sentia perseguido pela Igreja que eu acho que no cumprimento mesmo da sua posição de Igreja da maioria não é, e uma tradição de não deixar que os evangélicos, cristãos evangélicos, o protestantismo crescesse, então desde menino eu sentia essa pressão, por exemplo: a primeira investida que eu senti pesado, foi quando, interno do Colégio Cristão em Colinas né, eu me lembro que fomos apedrejados em um culto ao ar livre, na praça pública, enquanto realizávamos o culto, em Colinas, quando era estudante do Colégio Cristão com 17 anos. Mas não houve vez que eu sofri agressão por causa do evangelho, como os outros, não é? (Silva apud Veras, 2005, p. 58).
}

Assim como Dugal Smith, Abdoral Silva também deixou registrado os conflitos existentes em seu tempo escolar, destacando as investidas sofridas à própria escola. Veras (2005) chama a atenção para o fato de que os apedrejamentos em cultos ao ar livre não serem lembrados como "tão terríveis, o que nos leva a inferir sobre a adequação protestante a essa realidade e a pressupor que apedrejamentos eram comuns" (Veras, 2005, p. 58). 
Ainda nas memórias de Abdoral Silva, o destaque ao fato de que a presença dos protestantes e sua escola na cidade não só causou incômodo, quanto também o fato de que o grupo escolar procurou demarcar outros espaços, ao promover eventos públicos - cultos - na praça pública da cidade.

Numa perspectiva temporal de meio século, desde um processo de laicização do Estado em fins do século XIX às experiências no Colégio Cristão no Maranhão, percebemos as contradições encontradas entre um processo de normatização de leis à sua efetivação e conformação pela sociedade civil em pequenas localidades. Se, em âmbito nacional (ou nos grandes centros urbanos das regiões Sul e Sudeste do Brasil), a década de 1930 foi marcada por uma retomada de parceria do Estado brasileiro com a Igreja Católica, ainda que outras frentes religiosas tenham avançado, como o protestantismo, especialmente pela via educacional (Mesquida, 1994; Nascimento, 2007; Chamon, 2005; Hilsdorf, 1977), em regiões como o interior do Maranhão deste mesmo período, o processo de conquistas e enfrentamentos foram-Ihes novos, acontecendo de forma acirrada pelos espaços públicos de circulação.

As escolas protestantes, por sua vez, ainda que tenham se apresentado a partir de demandas sociais, frente ao analfabetismo local e a ausência de escolas na região, também foram palco das disputas pelo espaço público. $O$ estabelecimento destas escolas no interior do Maranhão, tomando pelas experiências das escolas de Eva Mills, fizeram parte diretamente do enfrentamento e da conformação de novas realidades que se apresentavam a partir de conflitos religiosos. Essa disputa por espaços, justificou desde a instalação dessas escolas, ao passo que os novos convertidos não eram bemvindos nas escolas de confissão católica, quanto evidenciam também as experiências de seus alunos diante das comunidades em que se encontravam.

\section{Considerações finais}

O início de um estado laico com uma diversidade religiosa não foi garantia de práticas pedagógicas democráticas, que muito das vezes eram prescritas em regulamentos que controlavam comportamentos e separavam espaços.

$\mathrm{Na}$ construção desse imaginário, o urbano, o escolar e o religioso se entrecruzaram sob a ótica dos dirigentes ou fundadores, que levantaram a bandeira do progresso e do moderno para ocupar um espaço social, muitas vezes disputado entre os concorrentes. Essa disputa nos primórdios não foi pacífica e nem democrática, principalmente com os católicos que não aceitavam a religião presbiteriana.

Pôde-se verificar uma diversidade de práticas pedagógicas visando uma formação humana, mas que, na maioria das vezes, não se fundamentava em ideários democráticos, prescrevendo normas de controle das ações coletivas e individuais dos alunos, que não participavam ativamente da construção dos regulamentos.

Os três estudos apresentados indicam que houve um entrelaçamento em que as escolas confessionais influenciaram e foram influenciadas pelas reformas educacionais, indicando uma aproximação entre o privado e o público nas formas de ensinar, organizar o currículo e estabelecer os espaços escolares. Nessa 
tríade, houve o estabelecimento de conflitos e normatizações que prescreveram deveres e direitos, num processo de Estado Democrático de Direito pós Proclamação da República que favoreceu uma diversidade cultural religiosa diferente da católica que imperou por muitos séculos.

Espera-se com esse artigo, alargar a compreensão de instalação do laicismo religioso em tempos em que as religiões se fazem presente no poder público, comprometendo o desenvolvimento de um Estado laico e de práticas democráticas conforme assegurados na Constituição.

\section{Referências}

A GAZETA. Lavras, 11 set. 1931.

Abreu, Geysa Spitz Alcoforado de. (2003). Escola Americana de Curitiba (18921934): um estudo do americanismo na cultura escolar. Dissertação de mestrado. PUC/SP.

Abreu, Geysa Spitz Alcoforado de. (2011). O Ensino regular da Caligrafia: a experiência da Escola Americana de Curitiba no Final do Século XIX e início do século XX. Revista HISTEDBR On-line, v. 43, p. 132-142.

Capri, Roberto. (1923). Estado do Paraná. São Paulo: Empresa Editora Brasil CAPRI \& OLIVERO.

Castro, Cesar Augusto; Silva, Diana Rocha da. (2016). A institucionalização dos grupos escolares no Maranhão. Revista Linhas. Florianópolis, v. 17, n. 33, p. 284308, jan./abr. 2016.

Chamon, Carla Simone. (2005). Maria Guilhermina Loureiro de Andrade: a trajetória profissional de uma educadora (1869/1913). Tese (doutorado) Universidade Federal de Minas Gerais, Faculdade de Educação. Belo Horizonte:

FaE.

Chartier, Roger. (2002). A história cultural, entre práticas e representações. Trad. Maria Manuela Galhardo, 2a ed. Difel editora. 2002. Coleção Memória e sociedade.

Cruz, Mariléia dos Santos. (2013). Ampliação e Modernização do sistema de ensino primário no interior do Maranhão. VII Congresso Brasileiro de História da Educação [anais].

Foucault, Michel. (2013). Vigiar e punir: história da violência nas prisões. Petrópolis, RJ: Vozes.

Gammon, Clara. (1959). Assim brilha a luz: a vida de Samuel R. Gammon. Lavras: Imprensa Gammon.

Goldman, Frank P. (1972). Os pioneiros americanos no Brasil: educadores, sacerdotes, covos e reis. Tradução: KRÁHENBÜHL, Olívia. São Paulo: Pioneira.

Hilsdorf, Maria Lúcia Spedo. (1977). Escolas americanas de confissão protestante na Província de São Paulo, um estudo de suas origens. Dissertação de Mestrado. São Paulo: USP. 
Hilsdorf, Maria Lúcia Spedo. (1986). Francisco Rangel Pestana: jornalista, político, educador. 1986. Tese (Doutorado) - Faculdade de Educação, Universidade de São Paulo. São Paulo.

Hunt, Lynn. (1995). A nova história cultural. São Paulo: Martins Fontes.

Julia, Dominique. (2001). A Cultura escolar como objeto histórico. Revista Brasileira de História da Educação. Tradução: Gizele de Souza. São Paulo: Autores Associados, n. 1, janeiro/junho, pp. 9-43.

Laguna, Shirley Puccia. (1999). Reconstrução histórica do Curso Normal da Escola Americana de São Paulo (1889-1933). Internato de meninas: uma leitura de seu cotidiano e da instrução e educação feminina aí ministradas. Dissertação de mestrado, Programa de História e Filosofia da Educação, da Pontifícia Universidade de São Paulo.

Maciel, M. M. (2018). Educación religiosa y regulaciones del cuerpo. History of Education in Latin America - HistELA, 1, e16404. Disponível em: https://periodicos.ufrn.br/histela/article/view/16404. Acesso em: 18 mar. 2020.

Melo, Sandra Maria Barros Alves. (2012). Percurso histórico da formação de professores para a escola primária no Maranhão: Império e República Velha. IX Seminário Nacional de Estudos e Pesquisas "História, sociedade e educação no Brasil" [anais], Universidade Federal da Paraíba - João Pessoa.

Mesquida, Peri. (1994). Hegemonia norte-americana e educação protestante no Brasil: um estudo de caso. Trad. Celso Rodrigues Filho. Juiz de Fora: EDUJF; São Bernardo do Campo: Editeo.

Mills, Eva Yarwood. (1976). Eva. 8:28. Lancaster: Brookshire Publications. Mills, Eva Yarwood. (1985). Entrevista concedida a Charles Stoner em 25 de março de 1985.

Nascimento, Ester Fraga Carvalho. (2007). Educar, Curar, Salvar. uma ilha de civilização no Brasil tropical. Maceió: Editora da Universidade Federal de Alagoas.

Nunes, Maria Thetis. (1992). Ensino secundário e sociedade brasileira. São Cristóvão: Ed. Universidade Federal de Sergipe.

O INSTITUTO. Lavras, jun. 1931.

PROSPECTO das Escolas do Instituto Evangélico. Biblioteca do Instituto Presbiteriano Gammon. Lavras, 1925.

PROSPECTO do Instituto Evangélico. Biblioteca do Instituto Presbiteriano Gammon. Lavras, 1921.

PROSPECTO do Instituto Evangélico. Biblioteca do Instituto Presbiteriano Gammon. Lavras, 1925.

PROSPECTO do Instituto Evangélico. Casa Editora Presbyteriana: Lavras, 1908.

PROSPECTO INSTITUTO GAMMON. Biblioteca do Instituto Presbiteriano Gammon. Lavras, 1937.

Silva, Abdoral Fernandes da. (1997). Nossas raízes: a história da Aliança das Igrejas Cristãs Evangélicas do Norte do Brasil (AICENB). 2 ed. São Luís.

Smith, Dugal. (1986). Fazendo progresso. São Paulo: Imprensa Batista Regular. 
Souza, Rosa Fátima de. (1998). Templos de civilização: a implantação da escola primária graduada no Estado de São Paulo (1890-1910). São Paulo: Fundação Editora da Unesp.

Vago, Tarcísio Mauro Vago. (2002). Cultura escolar, cultivo de corpos: educação physica e gymnastica como práticas constitutivas dos corpos de crianças no ensino público primário de Belo Horizonte (1906-1920). Bragança Paulista: EDUSF.

Veiga, Cynthia Greive. (2002). A escolarização como projeto de civilização. Revista Brasileira de Educação, Rio de Janeiro, n. 21, p. 90-103, set./dez. 2002.

Veras, Loyde Anne Carreiro Silva. (2017). Memórias da Terra de Beulá: a construção de uma vida e produção de um lugar nas autobiografias de Eva Mills. 2017. Dissertação (Mestrado em Educação). Escola de Educação e Humanidades. Pontifícia Universidade Católica do Paraná - PUCPR, Curitiba, 2017.

Veras, Rogério de Carvalho. (2005). Entre bodes e embatinados: representações de um conflito religioso no Maranhão. [monografia] Curso de História da Universidade Federal do Maranhão. - São Luís.

Warde, Mirian Jorge. (2001). Americanismo e Educação: a fabricação do "homem novo". Projeto de pesquisa desenvolvido no Programa EHPS - PUC-SP, com apoio da Capes e do CNPq.

\section{Notas}

\footnotetext{
' Samuel Rhea Gammon nasceu em 30 de março de 1865, em Bristol, Estado da Virginia e veio para o Brasil em 23 de novembro de 1889.

" Charlotte Kemper nasceu em Warrenton, Virginia, em 21 de agosto de 1837 e veio para o Brasil em 1882.

iii Os "Prospectos" foram livretos impressos na tipografia do Instituto com o objetivo de trazer todas as informações necessárias para os alunos sobre as escolas que compunham o sistema educacional presbiteriano em Lavras. Ele começou a ser publicado em 1903 e a última publicação encontrada na Biblioteca do Instituto Presbiteriano Gammon foi de 1971-1972.

iv Instituído em 2 de dezembro de 1837 como Colégio Pedro II, por Bernardo Pereira de Vasconcelos - ministro da Educação -, teve por propósito ser um modelo do Ensino Secundário do Império e um padrão a ser copiado pelas províncias. (cf. Nunes, 1992).

${ }^{v}$ Optou-se por manter a grafia original presente nos prospectos.

${ }^{v i}$ A carta de um pai datada de 30 de agosto de 1914 escrita ao diretor do Instituto, A. F. Shaw, toda a responsabilidade para que todas as medidas disciplinares cabíveis pudessem ser tomadas, indicando que o seu filho era indisciplinado: "[...] Confiado na capacidade, idoneidade e competência do estabelecimento por V.S. tão bem dirigido e com tão excelentes auxiliares; alimentam toda a esperança de que meu filho José, receba ahi a educação que não soubemos the dar, essa esperança continuo a concernar e transmitindo a sua pessoa toda a minha autoridade fraterna, venho pedir ao amigo que a empregue com toda a energia e rigor em beneficio do meo José, que muito criança, não compreende os dirigentes que mi causa e não critério e [...] que eu espero adquirirá em os vossos paternaes e criteriosos conselhos. Muito [...] ficará a minha gratidão se o amigo [...] ao meo pedido empregar as medidas necessárias a correção do menino. Muito esperançoso espero melhores noticias e [...] Jacintho A. da Silva (Escrevo hoje ao menino)." (PróMemória do Instituto Gammon).

vii Foucault (2013, p. 105), ao analisar os castigos físicos se refere à "mitigação": "Para isso, é preciso que o castigo seja achado não só natural, mas interessante; é preciso que cada um possa ler nele sua própria vantagem. Que não haja mais essas penas ostensivas, mas inúteis. Que também cessem as penas secretas; mas que os castigos possam ser vistos como uma retribuição que o culpado faz a cada um de seus concidadãos pelo crime com que lesou a todos, como penas "continuamente apresentadas aos olhos dos cidadãos", e evidenciem a utilidade pública dos movimentos comuns e particulares".
} 
viii Para a consecução dessa perspectiva foram utilizadas fontes legais localizadas no Departamento Estadual de Arquivo Público do Paraná - DEAP; fontes da Divisão de Documentação Paranaense, da Biblioteca Pública do Paraná. Ressalta-se que a principal base documental desse trabalho foi extraída do acervo privado, conservado pela família do exproprietário da Escola, O Rev. Luiz Lenz de Araújo Cesar. Este foi o primeiro estudo elaborado com base na documentação original da Escola.

ix Algumas destas conquistaram reconhecimento na educação brasileira, como Miss Márcia Browne, que colaborou com Caetano de Campos na Reforma do ensino público paulista, em 1890. $x$ Tais escolas também teriam por finalidade angariar novos candidatos ao trabalho evangélico: os meninos para o ministério e as meninas para o ensino. A formação de novos missionários era uma necessidade para a continuidade do trabalho das igrejas, sendo esta uma preocupação que aparece reiteradamente nos relatórios dos missionários.

${ }^{x i}$ Eva Mills só se filiou em 1940 à Unevangelized Fields Mission - UFM. A biografia de Eva Mills e suas escolas é associada à história da Aliança das Igrejas Cristãs Evangélicas do Brasil por meio de seus alunos e do grupo que ela ajudou a formar no Brasil (Silva, 1997). 